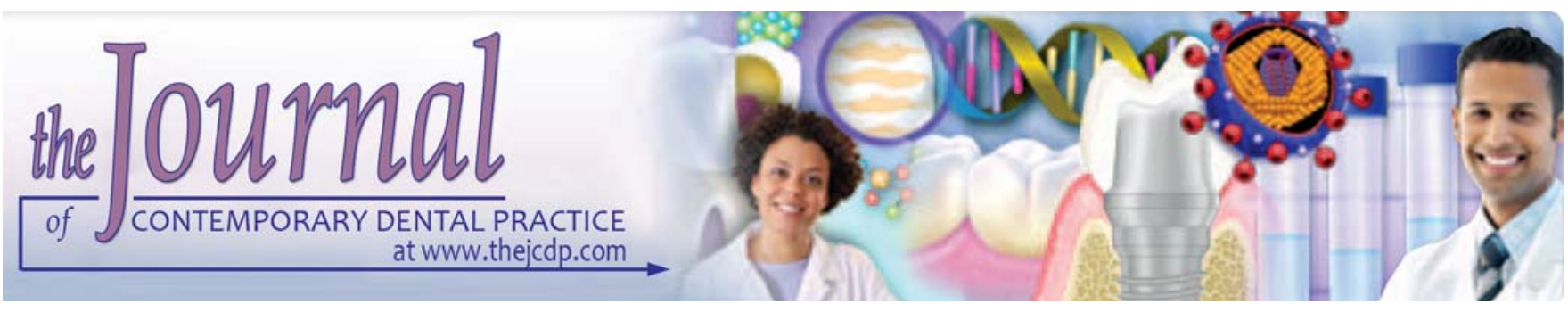

\title{
The Influence of Tray Space and Repeat Pours on the Accuracy of Monophasic Polyvinylsiloxane Impression
}

\author{
Anand Rajapur, Santosh Dixit, Chetan Hoshing, Sonal Raikar
}

\begin{abstract}
Aim: While literature demonstrates that the optimum accuracy is obtained with the custom trays, the use of stock trays for elastomeric impressions appears to be popular in general practice. The aim of the study was to evaluate the effect of thickness of impression material on the dimensional accuracy of impressions made from monophasic polyvinylsiloxane impression material. This study also studies the dimensional stability of the impressions poured at different time intervals.
\end{abstract}

Materials and methods: A metal model simulating two abutment teeth was fabricated along with reference lines inscribed on them. Custom impression trays were fabricated with spacer thickness of 2, 4 and $6 \mathrm{~mm}$. impressions were made using monophasic polyvinyl siloxane impression material. The impressions were poured and stone models were obtained. The dimensional accuracy of the impressions were determined indirectly by measuring the dimensional changes of the recovered stone models. The dimensional stability was also evaluated by pouring the impressions at time intervals of 1 hour, 24 hours and 7 days. The obtained data was statistically analyzed.

Results: The results of the study indicated that the impressions made from 2 and $4 \mathrm{~mm}$ tray space produced more accurate stone models when compared to $6 \mathrm{~mm}$ tray space. There was no significant deviation in the mesiodistal and buccolingual dimensions when impressions were made using impression trays with 2, 4 and $6 \mathrm{~mm}$ tray spacers. There was a significant decrease in interabutment distance $(p=0.001)$ and height of the abutment $(p=0.024)$ when impressions were made using impression trays with a tray space of $6 \mathrm{~mm}$. There were no significant differences found among the stone models obtained from 1 hour, 24 hours and 1 week pour times.

Conclusion: The mesiodistal and buccolingual dimensions of the abutments were not affected by the variations in thickness of impression material. There was a decrease in the height of the abutment which was clinically not significant. As the thickness of the impression material increased, the interabutment space decreased, which is a factor of concern when impressions are made for fixed partial dentures.

Clinical significance: When monophasic polyvinylsiloxane is used as the impression material, stock trays can be used for making impressions for individual castings.
Keywords: Tray space, Dimensional accuracy, Impression, Polyvinylsiloxane, Stock tray.

How to cite this article: Rajapur A, Dixit S, Hoshing C, Raikar $S$. The Influence of Tray S pace and Repeat Pours on the Accuracy of Monophasic Polyvinylsiloxane Impression. J Contemp Dent Pract 2012;13(6):824-829.

Source of support: Nil

Conflict of interest: None declared

\section{INTRODUCTION}

The precision fit of the dental prosthesis depends primarily on the accuracy of the dental impression material. The accuracy and dimensional stability of elastomeric impression materials has been the subject of numerous investigations. ${ }^{1-3}$ Currently, monophasic polyvinylsiloxanes are introduced to the dental profession as a dental impression material specially formulated for a one step, single mix impression technique.

Despite its excellent accuracy and performance, stock trays are used with an addition silicone only in putty wash technique. Previous studies reported undesirable dimensional changes and inaccuracies of the stone casts resulting from excessive uneven thickness of the elastomeric impression material when stock trays were employed. ${ }^{1,2}$

M onophasic polyvinylsiloxanes are basically formulated to be used for both tray and syringe, in a single-mix technique. The custom impression tray has long been considered necessary to provide uniform thickness of impression material. ${ }^{4,5}$ There is no universal agreement as to the optimal thickness of tray spacer. Different researchers recommended varying amounts of space ( 1 to $5 \mathrm{~mm}$ ) that would provide the most dimensionally stable and accurate impressions. ${ }^{1}$ U nfortunately, there has been little agreement on the optimal thickness of the impression material as it affects accuracy. ${ }^{1,4,6-10}$ 
This study has been designed to find the effect of different tray spacer thickness on the accuracy and the dimensional stability of impressions made from monophasic polyvinylsiloxane impression material.

\section{MATERIALS AND METHODS}

Monophasic polyvinylsiloxane (Provil Novo; Heraeus kulzer, Inc, USA ) was the impression material used in this study.

\section{Metal Die}

A machined standard stainless steel die with two truncated cone-shaped abutments was made to serve as a model simulating a three unit fixed partial denture. The model used in this study was similar to the design described by J ohnson and Craig. ${ }^{11}$ Reference lines were inscribed on the top and axial surfaces of the two truncated cone-shaped abutments to facilitate measurements (Figs 1 to 3 ).

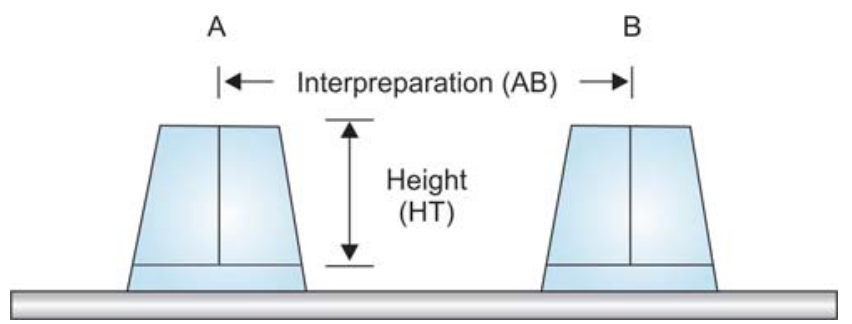

Fig. 1: Schematic diagram of the metal master modelfrontal view

B

M

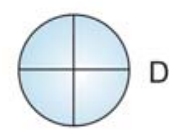

$\mathrm{L}$

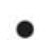

Fig. 2: Schematic diagram of the metal master modelocclusal view

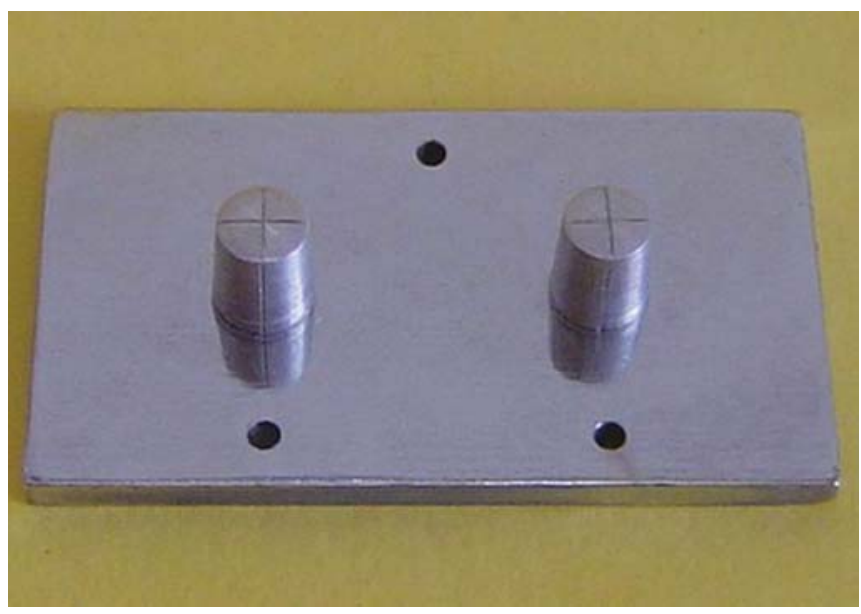

Fig. 3: Metal master model with reference lines inscribed

\section{Impression Trays}

Perforated polymethylmethacrylate resin trays, with 2, 4 and $6 \mathrm{~mm}$, respectively between the abutments and the inner tray walls, were fabricated using cold cure tray acrylic resin (N ew Stetic, Columbia) (Fig. 4). Threepins were incorporated in the resin trays to ensure correct tray centering and uniform material thickness. ${ }^{12}$

\section{Impression Making}

A thin, even coat of the tray adhesive (U niversal A dhesive; Heraeus kulzer) was applied to the inner surface and outer edges of the tray and was allowed to dry for at least 30 minutes. A one step, single mix impression technique was used. For each tray space, five impressions were made (Fig. 5). Thus, a total of 15 impressions were obtained.

\section{Pouring of Die Stones}

One hour after impression had set, it was boxed and poured with high strength dental stone, type IV (UltraRock, die stone class IV , K alabhai Karson Pvt Ltd India) (Fig. 6). It was repoured at 24 hours and then 7 days thereafter. Thus,

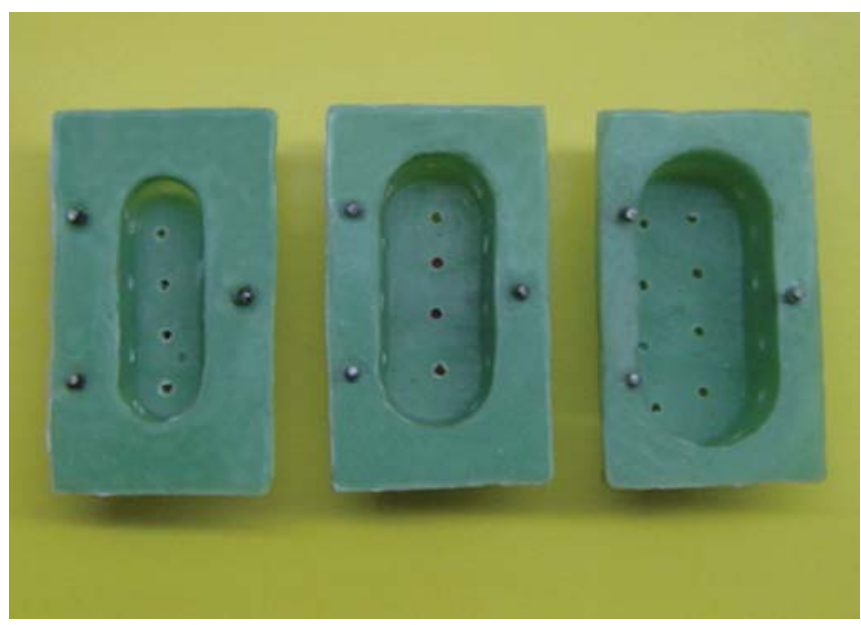

Fig. 4: Custom impression trays with 2, 4 and $6 \mathrm{~mm}$ tray space

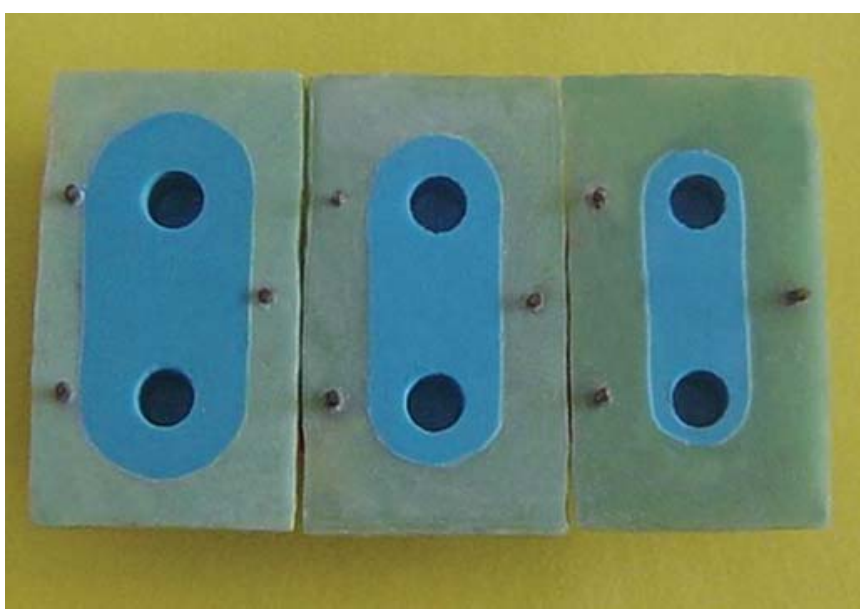

Fig. 5: Impressions made using 3 sizes of impression trays 


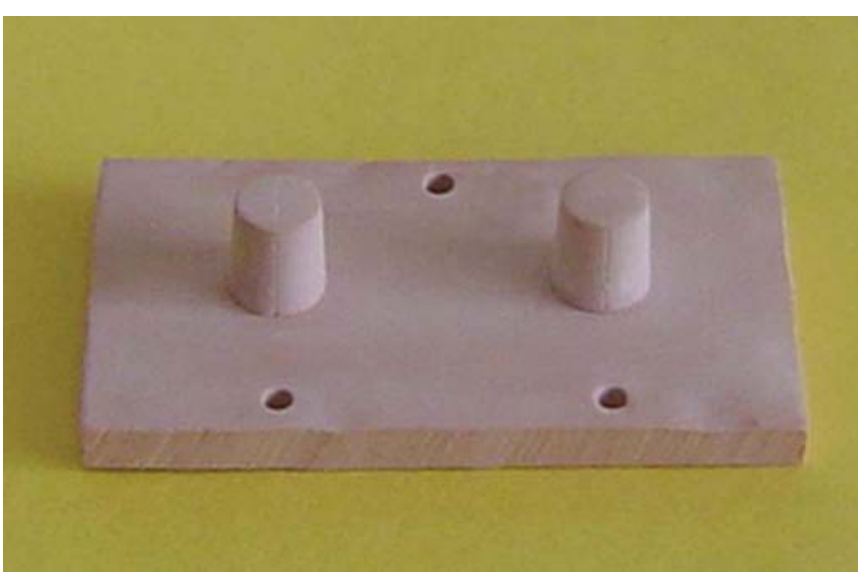

Fig. 6: Stone model

a total of 45 stone models were produced, which were labeled with combined numeric coding, for example, the tray space and pouring time were coded by numbers.

\section{Assessing the Dimensional Accuracy}

The dimensional accuracy and stability of the impressions were determined indirectly by measuring the dimensional changes of the recovered stone dies using digital telescopic microscope (Fig. 7) capable of measuring up to $0.001 \mathrm{~mm}$ $(1 \mu \mathrm{m})$. Four critical dimensions were measured. Interabutment dimension (AB), mesiodistal (MD), buccolingual $(B L)$, height of one abutment $(H T)$. M easurement of each dimension of the stone model was repeated three times and the mean was used as the final measurement. To minimize inconsistency related to measuring using a microscope, this task was performed by the same operator. The difference between the mean dimensions of the stone dies and of the metal die was computed and was expressed as percent deviation $(\Delta \%)$. The obtained data was subjected to one-way analysis of variance (A N OVA); Fischer's test (F) was used to compare

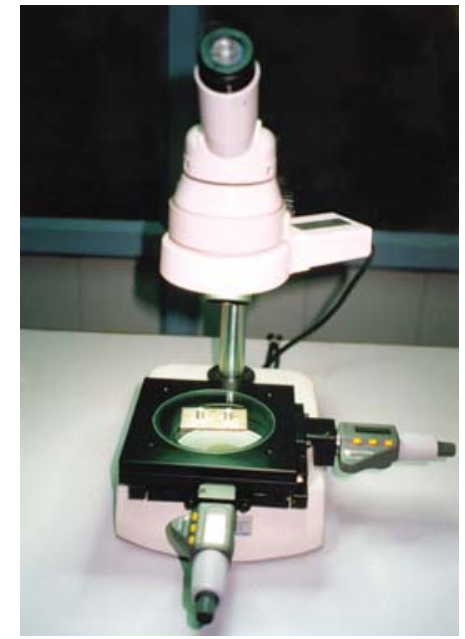

Fig. 7: Digital telescopic microscope the dimensions of the stone models recovered from impressions made using impression trays with 2, 4 and $6 \mathrm{~mm}$ tray spaces. M ultiple group comparison was done by Tukeys HSD test.

\section{RESULTS}

Table 1 shows the comparison of interabutment distance, mesiodistal dimension, buccolingual dimension and height of the metal model with the recovered stone models. It shows the mean, standard deviation and percentage deviation from the metal model along with $\mathrm{F}$-value and $\mathrm{p}$-values.

\section{Interabutment Distance}

The findings of the study conducted showed that there is decrease in interabutment distance. $B$ ut the decrease in the interabutment distance was not significant when impression was made using 2 and $4 \mathrm{~mm}$ tray space. The decrease was very highly significant $(p=0.001)$ for $6 \mathrm{~mm}$ tray space.

\section{Mesiodistal Dimension}

This study showed that the actual deviations of mesiodistal dimension for 2, 4 and $6 \mathrm{~mm}$ tray space when impressions were poured at 1 hour were mean values of $0.002,0.003$ and $0.013 \mathrm{~mm}$ with percentage deviations of $0.033,0.049$ and 0.215 . These values show that there is increase in the mesiodistal dimension. Statistical analysis showed no significant differences among the three tray spaces.

\section{Buccolingual Dimension}

The findings of the present study showed that the actual deviations of buccolingual dimension for 2, 4 and $6 \mathrm{~mm}$ tray spaces were mean values of $0.002,0.003$ and $0.006 \mathrm{~mm}$ with percentage deviations of $0.033,0.049$ and 0.099 . There is increase in the buccolingual dimension. The amount of increase was not significant statistically.

\section{Height}

This study showed that the deviations of height for 2, 4 and $6 \mathrm{~mm}$ tray spaces were mean values of $-0.007,-0.006$ and $-0.016 \mathrm{~mm}$ with percentage deviations of $-0.099,-0.090$ and -0.241 . These values show that there is decrease in the height of the abutment. Statistical analysis showed that there were no significant differences among 2 and $4 \mathrm{~mm}$ tray spaces, whereas statistically significant difference $(p=0.024)$ existed for $6 \mathrm{~mm}$ tray space when compared to metal model.

There was no significant difference in any of the dimensions when the pouring times were compared with each other. 
The Influence of Tray Space and R epeat Pours on the Accuracy of Monophasic Polyvinylsiloxane Impression

Table 1: Comparison of the four-dimensions obtained from the stone models showing mean, standard deviation, percentage deviation from metal model

\begin{tabular}{|c|c|c|c|c|c|c|c|c|c|c|c|c|c|}
\hline \multirow[t]{2}{*}{$\begin{array}{l}\text { Material } \\
\text { thickness }\end{array}$} & \multirow[t]{2}{*}{$\begin{array}{l}\text { Pour } \\
\text { time }\end{array}$} & \multicolumn{3}{|c|}{$\begin{array}{l}\text { Interabutment }(A B) \\
(22.736 \mathrm{~mm})\end{array}$} & \multicolumn{3}{|c|}{$\begin{array}{l}\text { Mesiodistal (MD) } \\
(6.032 \mathrm{~mm})\end{array}$} & \multicolumn{3}{|c|}{$\begin{array}{c}\text { Buccolingual (BL) } \\
(6.008 \mathrm{~mm})\end{array}$} & \multicolumn{3}{|c|}{$\begin{array}{l}\text { Height (HT) } \\
(6.634 \mathrm{~mm})\end{array}$} \\
\hline & & $\begin{array}{l}\text { Mean } \\
(\mathrm{mm})\end{array}$ & SD & Dev $(\%)$ & $\begin{array}{l}\text { Mean } \\
(\mathrm{mm})\end{array}$ & SD & $\operatorname{Dev}(\%)$ & $\begin{array}{l}\text { Mean } \\
(\mathrm{mm})\end{array}$ & SD & $\operatorname{Dev}(\%)$ & $\begin{array}{l}\text { Mean } \\
(\mathrm{mm})\end{array}$ & SD & $\operatorname{Dev}(\%)$ \\
\hline \multirow[t]{4}{*}{$2 \mathrm{~mm}$} & 1 & 22.733 & 0.006 & -0.013 & 6.034 & 0.006 & 0.033 & 6.010 & 0.006 & 0.033 & 6.627 & 0.006 & -0.099 \\
\hline & II & 22.731 & 0.005 & -0.023 & 6.034 & 0.005 & 0.033 & 6.011 & 0.006 & 0.049 & 6.626 & 0.006 & -0.121 \\
\hline & III & 22.730 & 0.006 & -0.026 & 6.035 & 0.006 & 0.049 & 6.011 & 0.007 & 0.049 & 6.624 & 0.007 & -0.151 \\
\hline & & \multicolumn{3}{|c|}{$\begin{array}{c}F=1.404 \\
p=0.278 \text { (NS) }\end{array}$} & \multicolumn{3}{|c|}{$\begin{array}{c}F=0.152 \\
p=0.927 \text { (NS) }\end{array}$} & \multicolumn{3}{|c|}{$\begin{array}{c}F=0.146 \\
p=0.931 \text { (NS) }\end{array}$} & \multicolumn{3}{|c|}{$\begin{array}{c}F=2.924 \\
p=0.066 \text { (NS) }\end{array}$} \\
\hline \multirow[t]{4}{*}{$4 \mathrm{~mm}$} & I & 22.730 & 0.006 & -0.026 & 6.035 & 0.006 & 0.049 & 6.011 & 0.006 & 0.049 & 6.628 & 0.007 & -0.090 \\
\hline & II & 22.728 & 0.007 & -0.036 & 6.037 & 0.005 & 0.082 & 6.012 & 0.007 & 0.067 & 6.625 & 0.006 & -0.136 \\
\hline & III & 22.726 & 0.008 & -0.044 & 6.038 & 0.007 & 0.099 & 6.012 & 0.007 & 0.067 & 6.623 & 0.006 & -0.163 \\
\hline & & \multicolumn{3}{|c|}{$\begin{array}{c}F=2.514 \\
p=0.095(N S)\end{array}$} & \multicolumn{3}{|c|}{$\begin{array}{c}F=0.642 \\
p=0.599(N S)\end{array}$} & \multicolumn{3}{|c|}{$\begin{array}{c}F=0.235 \\
p=0.871 \text { (NS) }\end{array}$} & \multicolumn{3}{|c|}{$\begin{array}{c}F=3.108 \\
p=0.056 \text { (NS) }\end{array}$} \\
\hline \multirow[t]{4}{*}{$6 \mathrm{~mm}$} & I & 22.705 & 0.007 & -0.136 & 6.045 & 0.006 & 0.215 & 6.014 & 0.012 & 0.099 & 6.618 & 0.013 & -0.241 \\
\hline & II & 22.703 & 0.006 & -0.145 & 6.048 & 0.010 & 0.265 & 6.015 & 0.012 & 0.116 & 6.617 & 0.015 & -0.256 \\
\hline & III & 22.702 & 0.005 & -0.150 & 6.048 & 0.015 & 0.265 & 6.017 & 0.010 & 0.149 & 6.608 & 0.012 & -0.386 \\
\hline & & \multicolumn{3}{|c|}{$\begin{array}{c}F=51.603 \\
p=0.001 \text { (VHS) }\end{array}$} & \multicolumn{3}{|c|}{$\begin{array}{c}F=2.521 \\
p=0.095 \text { (NS) }\end{array}$} & \multicolumn{3}{|c|}{$\begin{array}{c}F=0.562 \\
p=0.648 \text { (NS) }\end{array}$} & \multicolumn{3}{|c|}{$\begin{array}{c}F=4.199 \\
p=0.024(S)\end{array}$} \\
\hline
\end{tabular}

Pour time: I: 1 hour; II: 24 hours; III: 1 week; SD: Standard deviation; Dev (\%): Percentage of deviation; NS: Not significant; S: Significant; VHS: Very highly significant

\section{DISCUSSION}

$M$ aking an impression represents a crucial step in the quality of dental prostheses. For that reason, the accuracy of the impression is decisive for a precise final fit and consequently for the success of the dental reconstruction. Different scientific investigations have looked up at dimensional accuracy and dimensional stability of elastomeric impression materials. ${ }^{1,3,11,13-15}$ Elastomeric impression materials are commonly used because they are highly accurate and the most stable dental impression materials currently available. $3,7,16$ The introduction of single viscosity or monophasic polyvinylsiloxanes to the dental profession, which can be used both in the syringe and the tray, allows the number of consistencies to be reduced. Therefore, it is specially formulated for one-step, single-mix technique. The obvious benefit of this technique is that it is clinically simple. ${ }^{4,5,17} \mathrm{M}$ aking a custom tray requires planning, a study model, laboratory time, curing interval and finishing time. In contrast, the stock tray can be selected, adapted and used in a single visit for both an anticipated and unanticipated situation. There is no universal agreement as to the optimal thickness of tray spacer or impression material thickness. Different researchers recommended varying amounts of space $(1 \mathrm{to} 5 \mathrm{~mm}$ ) that would provide the most dimensionally stable and accurate impressions. ${ }^{1}$

The main cause for distortion of an impression is polymerization shrinkage of the impression material. The process of polymerization which involves cross-linking of polymer chains results in a reduction of spatial volume. This reduction of spatial volume results in dimensional changes of the impression. The direction of the dimensional change depends upon the bonding of the material to the impression tray.

The findings in the present study showed that there is decrease in interabutment distance $(A B)$, which may be accounted for by the polymerization shrinkage of the impression material toward the largest bulk lying in the area between the two abutments. This result is in agreement with the findings of Brosky ME et al, ${ }^{17}$ Rueda LJ et al ${ }^{18}$ and Tjan A HL et al. ${ }^{19}$ As the tray space is increased there is increase in percentage deviation which can be attributed to the larger bulk of impression material when compared to 2 and $4 \mathrm{~mm}$ tray space. The decrease in interabutment space for $6 \mathrm{~mm}$ tray space was statistically very highly significant $(p=0.001)$.

The actual deviations of mesiodistal dimension (MD) for 2, 4 and $6 \mathrm{~mm}$ tray space show that there is increase in the mesiodistal dimension. This increase can be attributed to the polymerization shrinkage of the impression material toward the largest bulk in the center and also to the polymerization shrinkage toward the impression tray walls because of the constraint induced on the impression material by an effective tray adhesive during curing of the impression material. Statistical analysis showed no significant differences among the three tray spaces. These results are in concurrence with the findings of Tjan AHL et al ${ }^{19}$ and Caputi $\mathrm{S}$ et al. ${ }^{20}$ Similar to the mesiodistal dimension there 
is an increase in the buccolingual dimension $(B L)$, which can be attributed to the polymerization shrinkage of the impression material toward the largest bulk in the center and al so the polymerization shrinkage tow ard the impression tray walls. Statistical analysis showed no significant differences among the three tray spaces and pour times for the mesiodistal dimension.

The findings show that there is decrease in the height of the abutment. This phenomenon can be attributed to the contraction of the impression material toward the impression tray walls, making the stone dies shorter in the vertical direction. This is in accordance with the findings of Gordon et $\mathrm{al}^{6}$ and Johnson GH et al. ${ }^{2}$ Statistical analysis showed that there were no significant differences among 2 and $4 \mathrm{~mm}$ tray spaces, where as statistically significant difference $(p=0.024$ ) existed for $6 \mathrm{~mm}$ tray space when compared to metal model. The greatest range of change $-0.386 \%$ was seen here. This represents a linear change of only $26 \mu \mathrm{m}$, which has questionable clinical significance. In consideration of die height alone, tray selection may be unimportant. ${ }^{6}$

There was no significant difference in any of the dimensions when the pouring times were compared with each other. Thongthammachat $S$ et al ${ }^{21}$ and Eduardo BF et $a^{22}$ reported similar findings regarding the dimensional stability.

From the findings it can be seen that the mesiodistal and buccolingual dimensions of the stone models obtained from the impression trays with 2, 4 and $6 \mathrm{~mm}$ tray spaces, did not show significant differences when compared to the metal model. Where as there was a significant decrease in the interabutment distance $(p=0.001)$ and height $(p=0.024)$ when impressions were made using impression trays with $6 \mathrm{~mm}$ tray space. It was also seen that there were no significant differences in the dimensions of the stone models poured at different time intervals. It is a very advantageous factor as the impressions do not have to be poured immediately but, can be poured over a longer period (within the time span investigated).

\section{CONCLUSION}

From the results of the foregoing study, it was observed that the impressions made using impression trays with 2 and $4 \mathrm{~mm}$ tray space produced more accurate stone models when compared to impression trays with $6 \mathrm{~mm}$ tray space. The stone models obtained from impressions made using impression trays with $6 \mathrm{~mm}$ tray space showed significant decrease in the interabutment distance $(p=0.001)$, while this decrease was not significant in trays with 2 and $4 \mathrm{~mm}$ tray space. It can be concluded that accurate and dimensionally stable impressions can be obtained for single castings from single mix technique utilizing stock impression trays and monophasic polyvinylsiloxane impression material. But the decrease in interabutment distance can result in potential problem when fixed partial denture is cast in one piece.

\section{CLINICAL SIGNIFICANCE}

From the above study, it may be seen that if monophasic polyvinylsiloxane impression material is used for impression making, a rigid stock tray may be a valid alternative to custom tray. B ut the decrease in the interabutment dimension is a cause of concern when the fixed partial dentures are cast in one piece.

\section{REFERENCES}

1. Eames W B, Sieweke JC, W allace SW, Rogers B L. Elastomeric impression materials: Effect of bulk on accuracy. J Prosthet Dent 1979;41:304-07.

2. Johnson GH, Craig RG. A ccuracy of addition silicone as a function of technique. J Prosthet Dent 1986;55:197-203.

3. Lacy A M, Bellman T, Fukui H, M alcolm Jendersen D. Timedependent accuracy of elastomeric impression materials. Part II: Polyether, polysulfides and polyvinylsiloxanes. J Prosthet Dent 1981;45:329-33.

4. A nusavice KJ. Phillip's science of dental materials (11th ed). St L ouis: W B Saunders 2003:214-13.

5. Craig RG, Powers J M : Restorative dental materials (11th ed). St Louis: M osby 2002:352-368.

6. Gordon G, J ohnson G, D rennon D. The effect of tray selection on the accuracy of elastomeric impression materials. J Prosthet Dent 1990;63:12-15.

7. Reisbick MH, Matyas J. The accuracy of highly filled elastomeric impression materials. J Prost Dent 1975;33:67-72.

8. Rosenstiel SF, Land MF, Junhei F. Contemporary fixed prosthodontics (3rd ed). St L ouis: M osby 2001:363-65.

9. Shillingburg HT J r, Sumiya H, W hitsett LD, Richard J, B rackett SE. Fundamentals of fixed prosthodontics (3rd ed). Quintessence Publishing Co Inc 1997;283:90.

10. V alderhaug J, Floystrand F. Dimensional stability of elastomeric impression materials in custom-made and stock trays. J Prosthet Dent 1984;52:514-17.

11. Johnson GH, Craig RG. A ccuracy of four types of rubber impression materials compared with time of pour and a repeat pour of models. J Prosthet Dent 1985;53:484-90.

12. Stackhouse James A. The accuracy of stone dies made from rubber impression materials. J Prosthet Dent 1970;24:377-86.

13. M arcinak CF, Draughn RA. Liner dimensional changes in addition curing silicone impression materials. J Prosthet Dent 1982;47:411-13.

14. Stackhouse James A. A comparison of elastic impression materials. J Prosthet Dent 1975;34:305-13.

15. Tjan A nthony $H L$, Whang Sung B, Tjan Albert $H$, Ruben $S$. Clinically oriented evaluation of the accuracy of commonly used impression materials. J Prosthet Dent 1986;56:4-8.

16. Clancy J M , Scandrett FR, Ettinger RL . L ong-term dimensional stability of three current elastomers. J Oral Rehabil 1983;10: 325-33. 
17. Brosky Mary E, Pesun Igor J, Lowder Phillip D, Ralph D, Hodges James $S$. L aser digitization of casts to determine the effect of tray selection and cast formation technique on accuracy. J Prosthet Dent 2002;87:204-09.

18. Rueda LJ , Sy-M unoz JT, N ailor W P, Goodacre CJ, Swartz M L. The effect of using custom or stock trays on the accuracy of gypsum casts. Int J Prosthodont 1996;9:367-73.

19. Tjan Anthony $\mathrm{HL}, \mathrm{H}$ arold $\mathrm{N}, \mathrm{N}$ guyen Lan TP, Raymond $\mathrm{C}$. Effect of tray space on the accuracy of monophasic polyvinylsiloxane impressions. J Prosthet Dent 1992;68:19-28.

20. Caputi S, Varvara G. Dimensional accuracy of resultant casts made by a monophase, one-step and tw o-step, and a novel tw ostep putty/light-body impression technique: A n in vitro study. J Prosthet Dent 2008:99(4):274-81.

21. Thongthammachat S, M oore BK, B arco M T 2nd, Hovijitra S, B rown DT, A ndres CJ. Dimensional accuracy of dental casts: Influence of tray material, impression material and time. J Prosthodont 2002:11(2):98-108.

22. Franco $E B$, da Cunha LF, B enetti A R. Effect of storage period on the accuracy of elastomeric impressions. J Appl Oral Sci 2007;15(3):195-98.

\section{ABOUT THE AUTHORS}

\section{Anand Rajapur (Corresponding Author)}

A ssociate Professor, D epartment of Prosthodontics and Implantology V yas Dental College and Hospital, J odhpur-342001, Rajasthan, India e-mail: anandrajapur@ rediffmail.com

\section{Santosh Dixit}

A ssociate Professor, D epartment of Prosthodontics and Implantology PDU Dental College, Solapur, M aharashtra, India

\section{Chetan Hoshing}

Professor and Head, Department of Prosthodontics and I mplantology SDS K rishna Institute of M edical Sciences D eemed U niversity, K arad M aharashtra, India

\section{Sonal Raikar}

Senior Lecturer, Department of Prosthodontics and Implantology DY Patil Dental School, DY Patil K nowledge City, Pune, M aharashtra India 